Revista Iberoamericana. Vol. LXIV, Núms. 184-185, Julio-Diciembre 1998; 373-378

\title{
INTRODUCCIÓN. \\ 1898-1998: UN REMOLINO EN EL TIEMPO
}

\author{
POR \\ Aníbal GonzÁlez \\ The Pennsylvania State University
}

Yo suelo regresar eternamente al Eterno Regreso ...

-Borges, "El tiempo circular"

El siglo veinte, más historicista que el diecinueve, parece destinado a no terminar ni con una explosión ni con un gemido, sino con una orgía de conmemoraciones. Como lo sugiere la metáfora económica en el título de este número especial de la Revista Iberoamericana, es como si, a punto de cumplir el segundo milenio (según el calendario occidental), quisiéramos saldar cuentas con el pasado para entrar en el tercer milenio libres de toda deuda histórica. En el ámbito de la cultura y las letras de lengua española, hemos atravesado por la ambiciosa y controvertida efemérides del Quinto Centenario de 1492, y por supuesto venimos conmemorando desde aún antes los diversos centenarios modernistas: las publicaciones de Ismaelillo (1881) y de Azul... (1888), así como las muertes de los iniciadores del movimiento: Casal (1893), Martí y Gutiérrez Nájera (1895), y Silva (1896).

De hecho, bien puede ser que, de todas nuestras "cuentas pendientes" culturales, las más inmediatas y urgentes sean con el anterior fin de siglo, no sólo por un afán de paralelismo histórico, sino porque el final del siglo diecinueve marcó el inicio de una serie de procesos y circunstancias con las que todavía estamos lidiando. Procesos y circunstancias para las cuales el año de 1898, y específicamente la Guerra Hispanoamericana, que tuvo lugar entre los meses de abril a diciembre de ese año, ha venido a convertirse en símbolo. ¿Pero, precisamente cuáles fueron esos aludidos procesos y circunstancias? ¿Y qué ha venido a simbolizar realmente el 1898 ? En el primer ensayo de este número, Aída Beaupied se remite sagazmente a este problema, citando al historiador cubano Manuel Moreno Fraginals (quien a su vez alude a José Lezama Lima). Según Moreno Fraginals, en cuanto a los hechos del 98, "para Cuba aún no se ha hallado la definición exacta: como en los versos de Lezama Lima, Cuba parece escaparse cuando uno cree haber hallado la definición mejor" (293).

Sin lugar a dudas, el año de 1898 en general está aún por encontrar "su definición mejor", pues el mismo asume distintos significados según la perspectiva desde la cual se contemple. Para España, significó una derrota evidente aunque difícil de asimilar; para los Estados Unidos de Norteamérica, fue una victoria rápida y fácil que no dejó gran huella en su memoria histórica. Para todas las naciones de lo que ya se había dado en llamar 
Latinoamérica, el 1898, al inaugurar la hegemonía norteamericana en el hemisferio, marcó la confrontación con una idea de la modernidad más radical que la recibida de Europa por vía de Francia, y una honda crisis de confianza a todos los niveles, que Latinoamérica aún no ha logrado superar.

Con todo, la intensidad con la que se experimenta la memoria histórica del 98 varía mucho de país en país y de región en región. Fuera del Caribe, el 98 y su simbolismo se perciben de manera más distanciada, casi diríamos teórica, o se entremezclan con otros conflictos o agravios históricos, anteriores o posteriores, respecto a los Estados Unidos. En contraste, no hay otra nación latinoamericana donde el 98 sea todavía un asunto más vivo e inmediato que en Puerto Rico. El 98 marcó en Puerto Rico una honda división, no sólo entre períodos históricos, sino en la vida política y en el desarrollo de la identidad nacional. Como lo destacan los respectivos ensayos de Guillermo Irizarry y de César Salgado en torno a la novela La llegada (1980) de José Luis González, la división llega al extremo de que aún hoy día no hay acuerdo entre los puertorriqueños en cuanto a cómo calificar y enjuiciar lo que les pasó en ese año: ¿catástrofe? ¿bienandanza? ¿simple accidente histórico?

Un libro de muy reciente publicación nos ofrece, en contraste con el relato más bien conjetural de González, un testimonio íntimo y concreto de los efectos que tuvo la invasión sobre la conciencia de un puertorriqueño de aquella época. Se trata de Crónica del '98. El testimonio de un médico puertorriqueño (1998). Editado por las profesoras Luce y Mercedes López-Baralt, el mismo consiste en los recuerdos de la invasión norteamericana de Puerto Rico redactados por su bisabuelo, el médico Esteban López Giménez, en 1901. Galeno de vocación abnegada y temperamento reflexivo, López Giménez destaca en su testimonio el inmenso desgarramiento y los sentimientos encontrados que la invasión le ocasionó:

Yo estaba sumamente disgustado porque nunca fui simpatizador [de los pronorteamericanos], y sentía de todo corazón cambiar de nacionalidad; porque quise a España; no fui separatista, y si bien odiaba los gobiernos de España aquí, amaba a mi Madre Patria; a mi raza hispano latina; a mi religión católica apostólica romana; a mi idioma, tan rico, en el que he pensado, en el que me encomiendo a Dios pidiéndole la salvación de mi alma y de mi pobre tierruca (51).

Su dolor ante la ocupación, y lo que este suceso puso en evidencia en cuanto a las deslealtades y el oportunismo de sus coterráneos, incluso se le reflejó, según López Giménez, en afecciones somáticas: "Desde entonces acá mis dolencias se han agravado, mi sistema nervioso se ha echado a perder y no volveré a ser el que era nunca más" (61).

El hecho de que López Giménez perteneciera a la élite social y cultural del país en ese tiempo, no implica que su incertidumbre y desazón no hayan sido compartidas por muchos otros de sus compatriotas en distintos niveles de la sociedad. Ciertamente, el testimonio de López Giménez, junto a hechos de resistencia recogidos por la historia, como el de los capitanes puertorriqueños en el ejército español, Angel Rivero y Ramón Acha, que defendieron la ciudad de San Juan durante el bombardeo norteamericano del 12 de mayo de 1898 (Hernández 48-49), contradice el clisé historiográfico de que los norteamericanos invadieron la isla casi "a invitación" de los puertorriqueños, y que éstos últimos sólo 
manifestaron su desilusión dos años después, en el 1900, tras el régimen de tutelaje político establecido por la Ley Foraker.

Las rupturas entre familiares y amigos, las claudicaciones individuales y las tensiones sociales descritas por López Giménez, muestran el desasosiego que causó la invasión desde el principio. Además, la angustia expresada por el propio López Giménez - a pesar de sus evidentes lastres decimonónicos y de su puertorriqueñidad que no se atrevía a decir su nombre - resuena todavía en muchos de sus compatriotas, pues aún no existe el puertorriqueño que haya superado, en lo íntimo de su ser, el conflicto abierto por el 1898. Y, como advierte en el prólogo Luce López-Baralt, "las asimilaciones injustas y violentas dejan una herida perpetua abierta a la posibilidad de un intento de reivindicación igualmente inesperado" (26).

Podría argumentarse, no obstante, que el conflicto por el que atravesamos los puertorriqueños no es sino una versión más intensa y directa de aquel que experimentan todos los demás latinoamericanos, e incluso no pocos norteamericanos: la lucha entre la modernidad socioeconómica y el particularismo cultural, tanto a nivel individual como colectivo. No es necesario repetir lo que ya se ha escrito abundantemente sobre la modernidad como fenómeno avasallador, que procura transformarlo todo a su imagen y semejanza, y cuya imagen y semejanza es la de la constante crisis y el perpetuo cambio. En este sentido, es indudable que mucho antes de 1898 un grupo especialmente sensible de intelectuales de la América Hispánica, los modernistas, había comenzado a enfrentarse al reto de la modernidad. Más aún, cada día es mayor el convencimiento entre los estudiosos del modernismo de que ese grupo de escritores tuvo fundamentalmente éxito en su empresa de modernizar el quehacer literario hispanoamericano, y que por ello los modernistas son los legítimos e inmediatos precursores del florecimiento literario hispanoamericano del siglo veinte.

No es casual que en los últimos años se haya venido rehabilitando, incluso a niveles extraliterarios, la fama y la reputación otrora eclipsada de algunos de los principales autores modernistas. Por ejemplo, en 1995, la conmemoración del centenario de la muerte de Manuel Gutiérrez Nájera en la UNAM recibió una difusión en la prensa y un nivel de respaldo oficial inusitados para un autor del modernismo mexicano (Memoria Coloquio Internacional Manuel Gutiérrez Nájera y la Cultura de su Tiempo). Pero la conmemoración de la muerte de José Asunción Silva en Colombia el año siguiente fue mucho más lejos: además de celebrarse un simposio de una semana en la Casa de Poesía Silva de Bogotá con la asistencia de dos ex-presidentes y el actual mandatario colombiano, el día exacto del aniversario luctuoso, el 24 de mayo, se llevó a cabo un homenaje a Silva por todo el país, al cual se unieron las estaciones de radio y televisión y los periódicos, en una verdadera apoteosis que elevó al autor del "Nocturno" poco menos que al rango de poeta nacional (Silva, su obra y su época. Memoria del Congreso). Semejante consagración de un escritor notoriamente elitista y cosmopolita como lo fue Silva, probablemente respondía al deseo de reconciliar la modernidad literaria de éste con la búsqueda de la modernización socioeconómica que, en Colombia como en el resto de Latinoamérica, es hoy día la principal meta del gobierno y de las élites políticas. Dentro de la analogía implícita en esta rehabilitación, los modernistas, con su cosmopolitismo literario, serían los precursores autóctonos de la tan pregonada "globalización” económica. Tanto México y Colombia 
como la Nicaragua sandinista y postsandinista con Rubén Darío, han reivindicado y exaltado a sus poetas modernistas en gran medida porque han decidido abrazar también, con todos sus riesgos, la modernidad sin cortapisas predicada por el neoliberalismo.

Sin embargo, el texto de Rubén Darío, "El triunfo de Calibán" (1898), y la nota crítica de Carlos Jáuregui que lo acompaña, destacan cómo el cosmopolitismo modernista se transforma, a raíz del 1898, en un etnocentrismo deliberado y defensivo. Este hecho no disminuye la importancia del modernismo; por el contrario, es otro ejemplo de cómo estos autores marcaron la pauta del devenir cultural de Hispanoamérica en el siglo 20. Los ensayos aquí recogidos en torno al modernismo y su época testimonian de diversos modos el carácter fundacional del modernismo con respecto a la cultura hispanoamericana y española del siglo veinte. A la vez que exploran lo que el modernismo tuvo de moderno, examinan también lo que está muerto de ese movimiento (como la recitación de poesía) y lo que aún pervive (como el fenómeno del turismo y la crónica de viajes). Miguel Gomes examina el mecanismo de tópicos mediante el cual los modernistas urdían sus versos; Eduardo Jaramillo-Zuluaga estudia la costumbre de la recitación pública de la poesía; Alfonso García Morales estudia el legado transatlántico del modernismo en la obra crítica de Federico de Onís; Cristóbal Pera traza el dilatado impacto de la crónica de viajes modernista hasta nuestros tiempos, y Sylvia Molloy se remite a lo que podríamos llamar el uso y abuso (en el sentido más fuerte de este último término) de la figura de la mujer en la narrativa modernista. La violencia misógina que se patentiza en las dos novelas argentinas de principios de siglo veinte que estudia Molloy, es en gran medida una reacción masculina, como señala la estudiosa, al arribo a Latinoamérica de los ideales de la emancipación de la mujer.

Sin lugar a dudas, otro de los muchos "procesos y circunstancias" que tienen su inicio en los años que rodean a 1898 lo es también el fenómeno - en este caso, sumamente positivo- del crecimiento de una conciencia feminista latinoamericana y su expresión literaria. Aunque tampoco estuvo exenta de conflictos (recordamos cómo Clorinda Matto de Turner, por ejemplo, como algunas feministas latinoamericanas de la actualidad, se resistía a que la catalogaran de "feminista"; Lindstrom xii-xv), esta incipiente lucha por los derechos de la mujer es además ejemplo de una interacción fructífera con las corrientes culturales de la modernidad que emanaban de los Estados Unidos. Nutriéndose del acervo actual de la crítica feminista, los ensayos de Flora González, Magdalena García-Pinto y Mariselle Meléndez exploran los cambios en la construcción del sujeto femenino hispanoamericano desde la literatura de fines del siglo diecinueve y principios del veinte, hasta el arte cinematográfico de nuestro propio fin de siglo.

Los dos ensayos que cierran este número especial destacan los puntos de contacto que aún subsisten entre la literatura hispanoamericana de fines del siglo veinte y la de fines del siglo diecinueve, así como algunas diferencias significativas. El trabajo de Fernando Reati y Gilberto Gómez Ocampo subraya la extraordinaria continuidad y pervivencia de la visión "calibanesca" de los Estados Unidos gestada por los modernistas, a través del examen de una serie de novelas hispanoamericanas recientes que describen o tematizan el choque de los escritores latinoamericanos con el medio académico norteamericano. Reati y Ocampo demuestran que más allá del antiacademicismo generalizado que es común a la mayoría de los novelistas modernos en todos los países, aún subsisten en la novelística hispanoamericana 
presuntamente cosmopolita de estas últimas décadas los mismos estereotipos de los Estados Unidos manifestados por Darío en "El triunfo de Calibán" hace cien años. Es como si 1898 marcara un remolino en el tiempo, una especie de time warp de la ciencia-ficción, un tiempo circular que nos condenara a repetir perpetuamente los mismos gestos.

La obra de Alfredo Bryce Echenique, como sugiere el ensayo de Isabel Gallego que cierra este número, gira productivamente en torno a ese remolino temporal. No porque Bryce evoque directamente a 1898 (lo cual nunca hace), sino porque el gran novelista peruano manifiesta, en el entrelazamiento de su persona y su obra, y en las "geografías múltiples" de su espacio vital (para citar la acertada expresión de Gallego), un fenómeno que los modernistas también preludiaron: el desplazamiento como categoría del ser. Gallego incluso aplica explícitamente en su análisis el concepto de "globalización" a la obra de Bryce, la cual se mueve y se ramifica entre el Perú, Francia, España, y los demás países (Estados Unidos, Italia, Cuba, Puerto Rico) en los que ha vivido temporariamente.

Lo curioso es que esta suerte de nomadismo, que nos puede parecer tan posmoderno, ya lo habían experimentado y textualizado, como demuestra Cristóbal Pera en "De viajeros y turistas...", figuras capitales del modernismo como Silva, Darío y Gómez Carrillo. La diferencia con los precursores modernistas, en el caso de Bryce, radica en su aceptación de esta realidad y en su aprovechamiento visible de ella para forjar su obra narrativa, incorporando las lecciones de precursores más inmediatos, como Julio Cortázar, Carlos Fuentes, o su compatriota Julio Ramón Ribeyro. ¿No habrá una influencia bryceana, a la vez que una coincidencia de circunstancias de nuestro fin de siglo, en aquellas obras recientes donde aparece el escritor latinoamericano como una figura "globalizada", desde los Doce cuentos peregrinos (1992) de Gabriel García Márquez hasta La guagua aérea (1994) de Luis Rafael Sánchez, entre otros muchos?

Inevitablemente, el remolino del 1898-1998 irá disolviéndose en nuevos remolinos, en nuevas turbulencias hoy inimaginables. Los procesos iniciados en el 1898 seguirán por nuevos derroteros; tanto nuestra literatura como nuestras preocupaciones presentes irán pareciendo cada vez más arcaicas, tal como el modernismo le pareció alguna vez a los (entonces) jóvenes de las vanguardias o a los narradores telúricos de la década de los treinta. Vale la pena recordar que, así como hay fenómenos recurrentes que enlazan el pasado fin de siglo y el nuestro, otras presuntas similitudes entre ambos fines de siglo son en gran medida ilusorias, fruto de la tendencia humana de buscarle ritmos y concordancias al fluir del tiempo. Seguramente es demasiado pedir que, para el 2098, nuestros descendientes se hayan liberado del todo de la costumbre de urdir fantasías de un tiempo circular, pero será una inequívoca señal de salud el que éstas ya no giren en torno a cierto año de finales del siglo diecinueve.

Por lo pronto, hay algo muy concreto que podemos hacer los lectores de esta revista, tanto los que residimos en los Estados Unidos como en Latinoamérica, para ir poniéndole fin a una de las múltiples injusticias que aún hoy día sigue generando el remolino del 1898. Se trata del caso de quince puertorriqueños - hombres y mujeres, maestros, líderes comunitarias, artistas, trabajadoras, todos sin antecedentes criminales antes de su arrestoque extinguen condenas insólitamente largas (de entre 55 y 90 años de cárcel) en prisiones federales de los Estados Unidos, por el delito de abogar, con sus palabras y acciones, por la independencia de Puerto Rico. Estos prisioneros de conciencia intentaron saldar, a su 
mejor ver y entender, una deuda histórica con el 1898. Hoy nuestra deuda es con ellos. No se me ocurre mejor modo de conmemorar y a la vez ir subsanando las heridas históricas de hace cien años, que instar a los lectores de este número especial de la Revista Iberoamericana a unirse al grupo ya numeroso de entidades cívicas, figuras públicas y ciudadanos particulares de diversas convicciones políticas y religiosas, tanto en Puerto Rico como en los Estados Unidos y a nivel internacional, que abogan por la pronta reducción de sentencias o la excarcelación de Antonio Camacho Negrón, Edwin Cortés, Elizam Escobar, Ricardo Jiménez, Oscar LópezRivera, Adolfo Matos Antongiorgi, Dylcia Pagán, Alberto Rodríguez, Alicia Rodríguez, Ida Luz Rodríguez, Luis Rosa, Juan Segarra Palmer, Alejandrina Torres, Carlos Alberto Torres, y Carmen Valentín. Puede hallarse más información sobre estos prisioneros de conciencia puertorriqueños y cómo ayudarlos, en el siguiente sitio de la Internet: http:/www.wco.com/ boricua/POWS/.

NOTA: La portada de este número especial reproduce una caricatura del general Nelson A. Miles, comandante de la flota norteamericana que invadió Puerto Rico en 1898. En una notoria proclama a los puertorriqueños, Miles declaró que venía a traerles "las bendiciones de nuestra civilización [norteamericana]". La caricatura, con su poema satírico al pie, apareció en el libro del puertorriqueño Mario Brau, Trazos (1915).

\section{OBRAS CITADAS}

Borges, Jorge Luis. "El tiempo circular". Obras completas 1923-1972. Buenos Aires: Emecé, 1974, 393-96.

Hernández, Miguel J. "San Juan Under Siege”. Military History (abril de 1998): 46-52.

Lindstrom, Naomi. "Foreword". Clorinda Matto de Turner, Birds Without a Nest. Tr. de J.G.H.(sic), enmendada por Naomi Lindstrom. Austin: University of Texas Press, 1996, vii-xxi.

López-Baralt, Luce, y Mercedes López-Baralt. Crónica del '98. El testimonio de un médico puertorriqueño. Madrid: Ediciones Libertarias, 1998.

Memoria Coloquio Internacional Manuel Gutiérrez Nájera y la Cultura de su Tiempo. México: Instituto de Investigaciones Filológicas, UNAM, 1996.

Moreno Fraginals, Manuel. Cuba/España, España/Cuba. Historia común. Barcelona: Grijalbo Mondadori, 1995.

Silva, su obray su época. Memoria del Congreso. Número especial de Revista Casa Silva, 10 (1996). 